Supplement of Atmos. Chem. Phys., 16, 10441-10454, 2016

http://www.atmos-chem-phys.net/16/10441/2016/

doi:10.5194/acp-16-10441-2016-supplement

(C) Author(s) 2016. CC Attribution 3.0 License.

(c) (i)

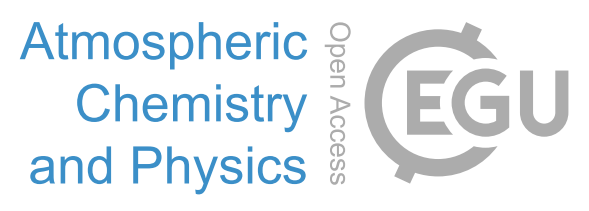

Supplement of

\title{
Vertical profiles of black carbon measured by a micro-aethalometer in summer in the North China Plain
}

\section{Liang Ran et al.}

Correspondence to: Liang Ran (shirleyrl@mail.iap.ac.cn) and Zhaoze Deng (dengzz@mail.iap.ac.cn)

The copyright of individual parts of the supplement might differ from the CC-BY 3.0 licence. 

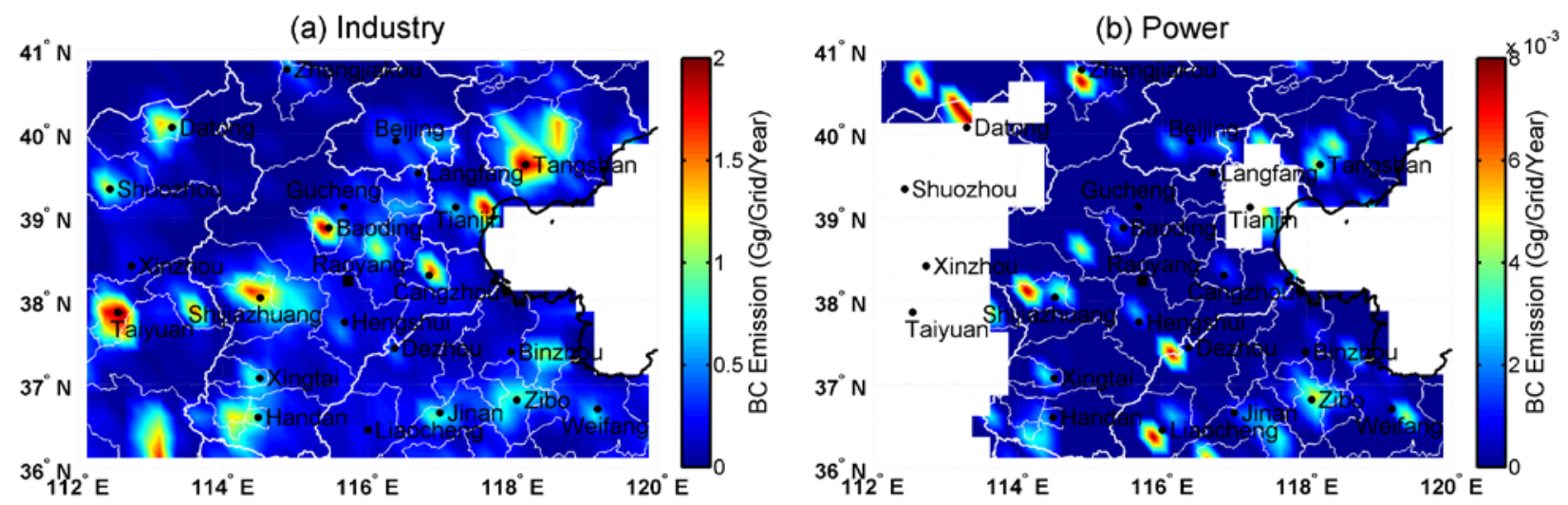

(c) Residential Activity
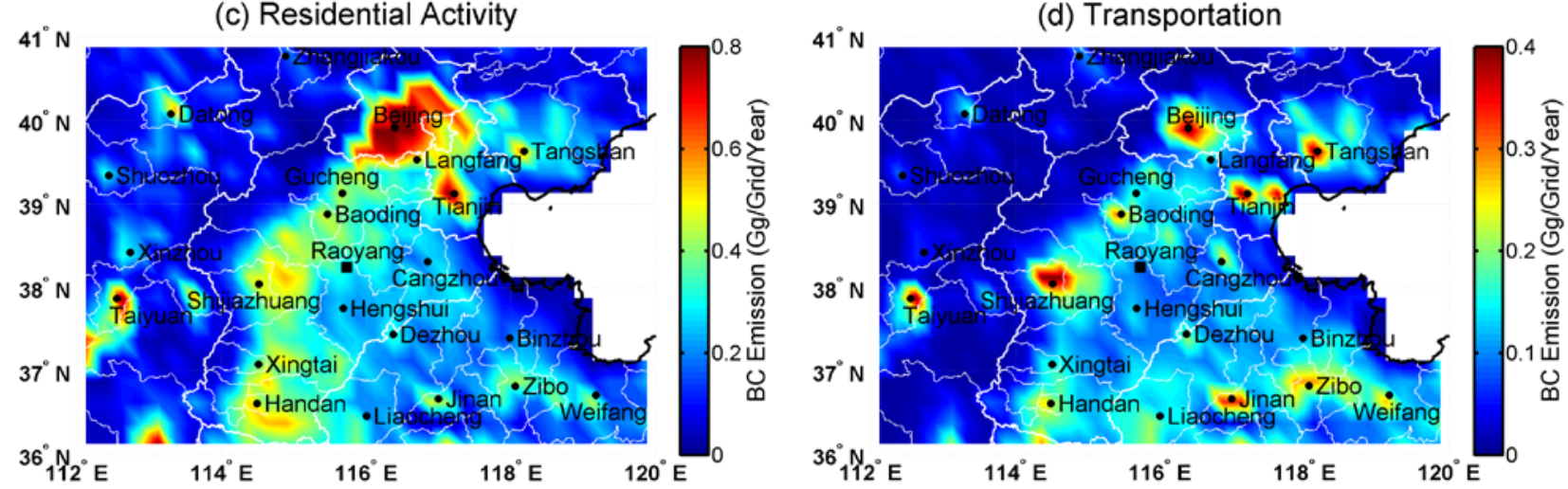

Figure S1. The spatial distribution of BC emissions from the sector of (a) Industry; (b) Power; (c) Residential Activity; (d) Transportation, based upon the emission inventory from the MEIC Model. 


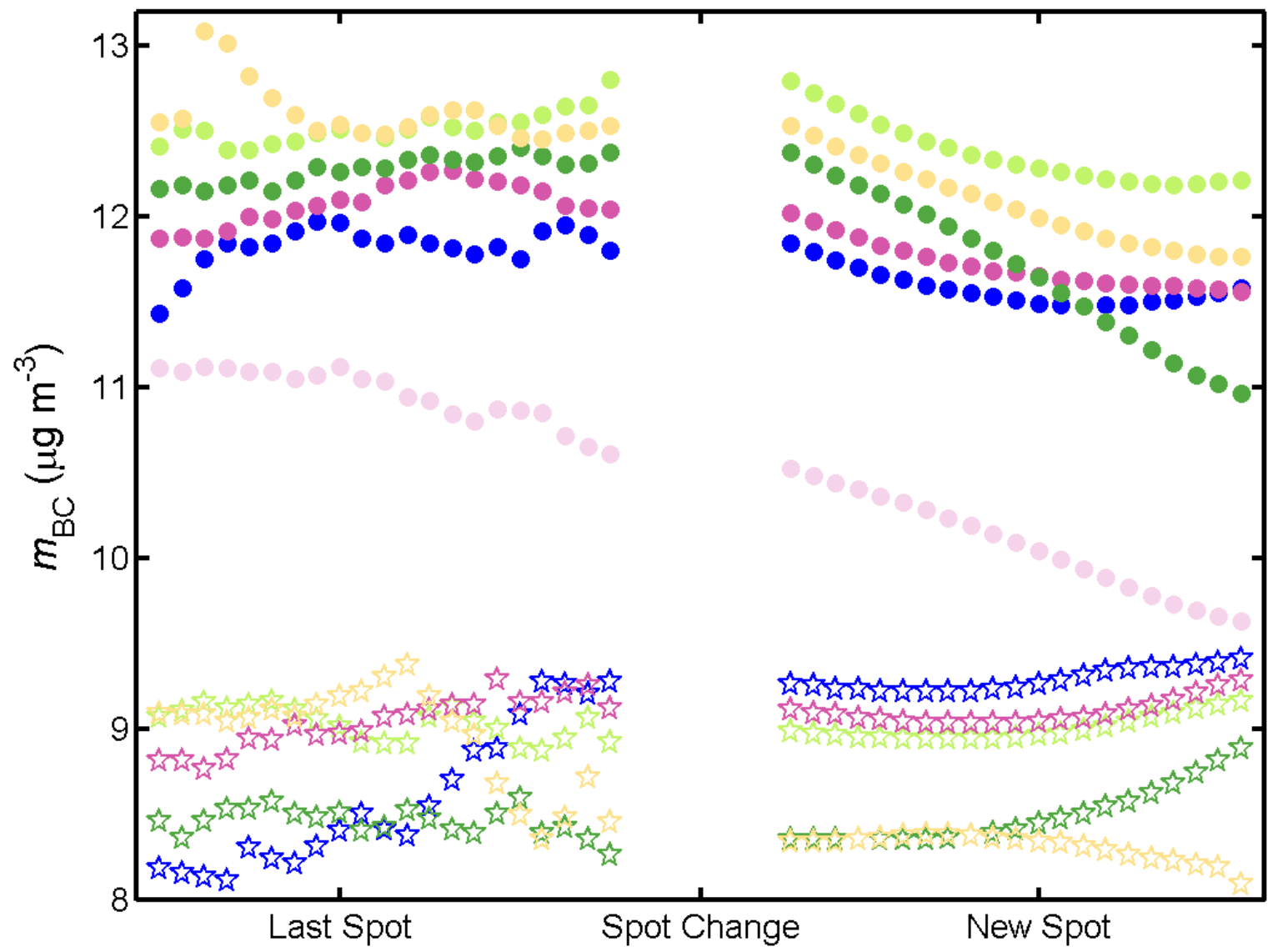

Figure S2. A comparison between measurements using MAAP across filter spot changes for cases where BC mass concentrations exceeded 8 ug $\mathrm{m}^{-3}$. Data points (with a temporal resolution of $1 \mathrm{~min}$ ) collected before and after a spot change were denoted by the same marker in the same color. 


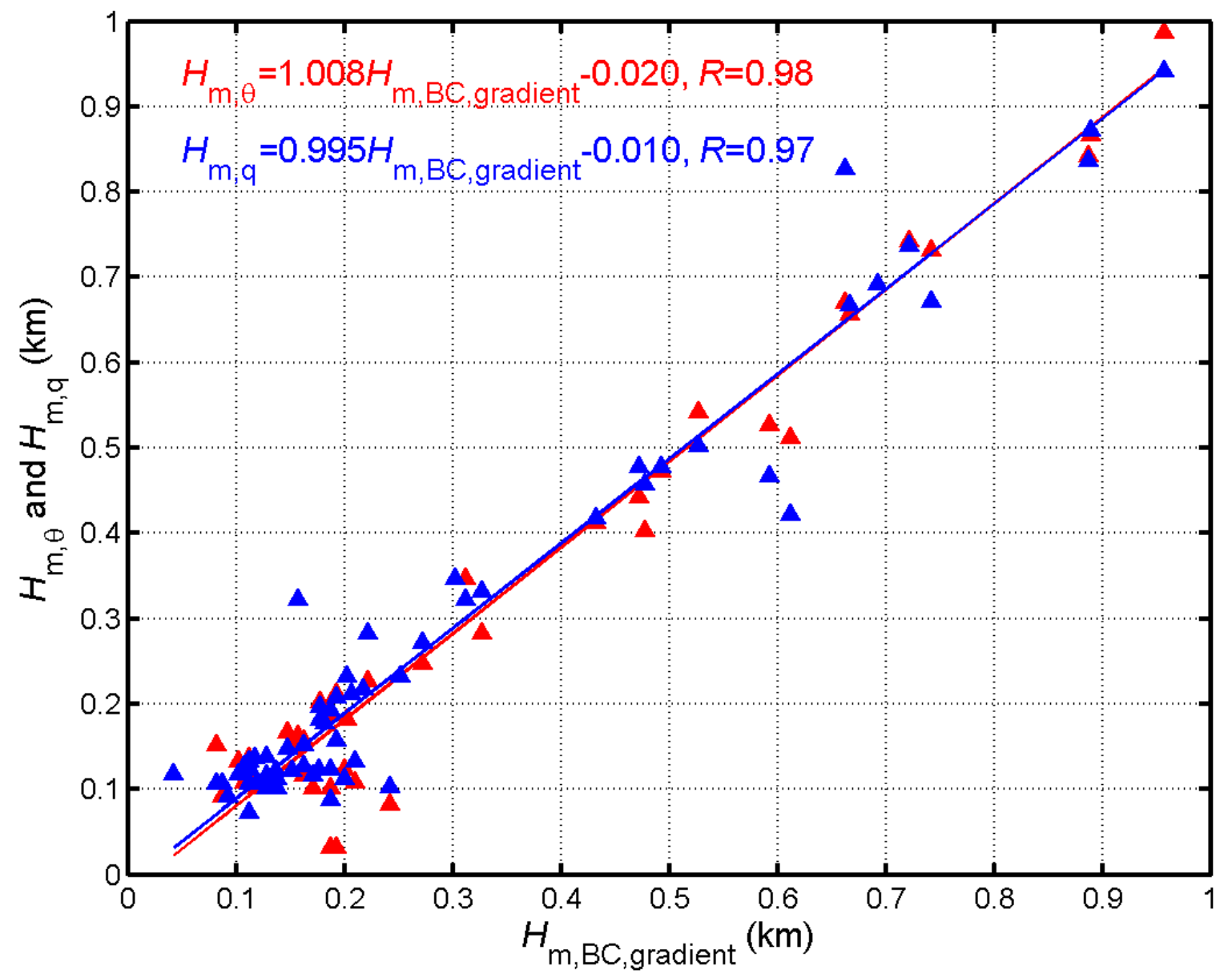

Figure S3. A comparison among mixing heights estimated from vertical profiles of $m_{\mathrm{BC}}$ using the gradient method ( $\left.H_{\mathrm{m}, \mathrm{BC}, \text { gradient }}\right)$ and that of $\theta\left(H_{\mathrm{m}, \theta}\right)$ and $q\left(H_{\mathrm{m}, \mathrm{q}}\right)$ for the entire dataset. 


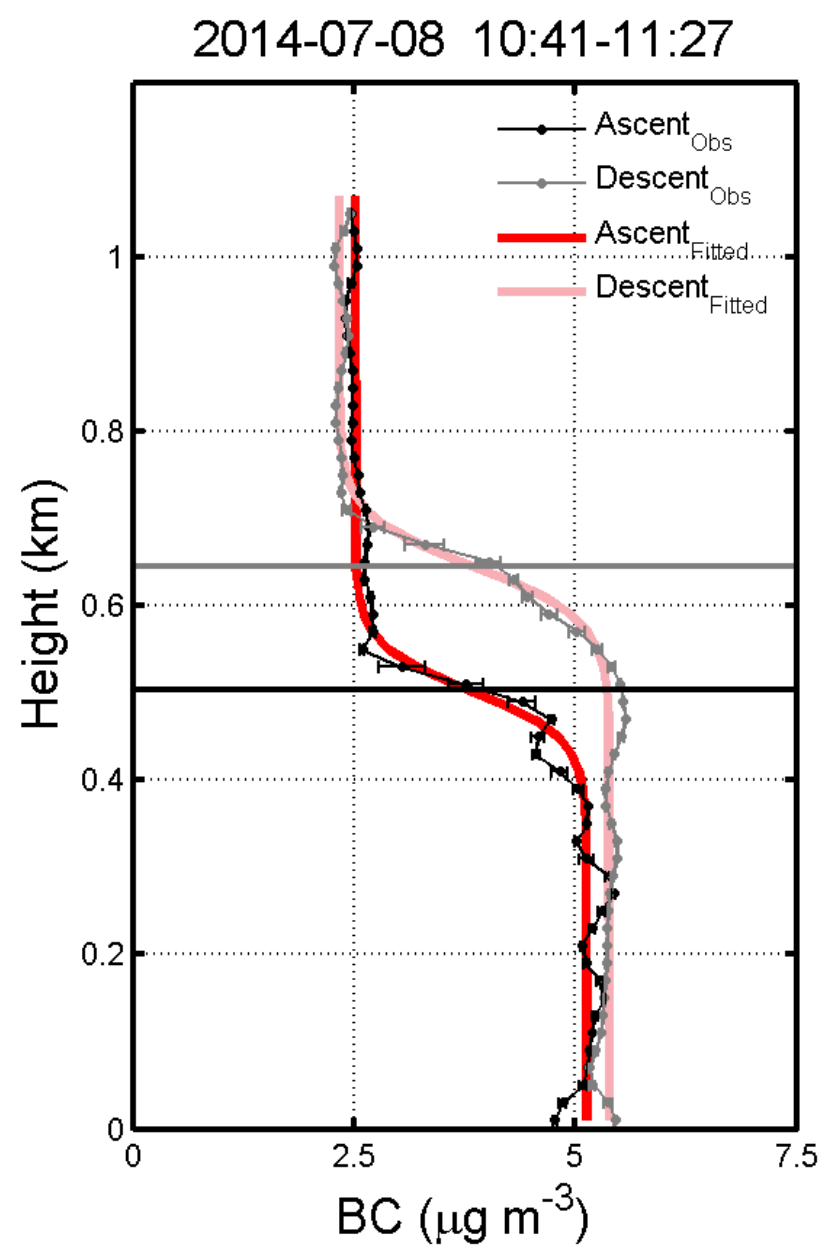

Figure S4. An example of fitting BC vertical profiles using the sigmoid function. Measurements were conducted on July 8, 2014 (10:41-11:27 LT). 


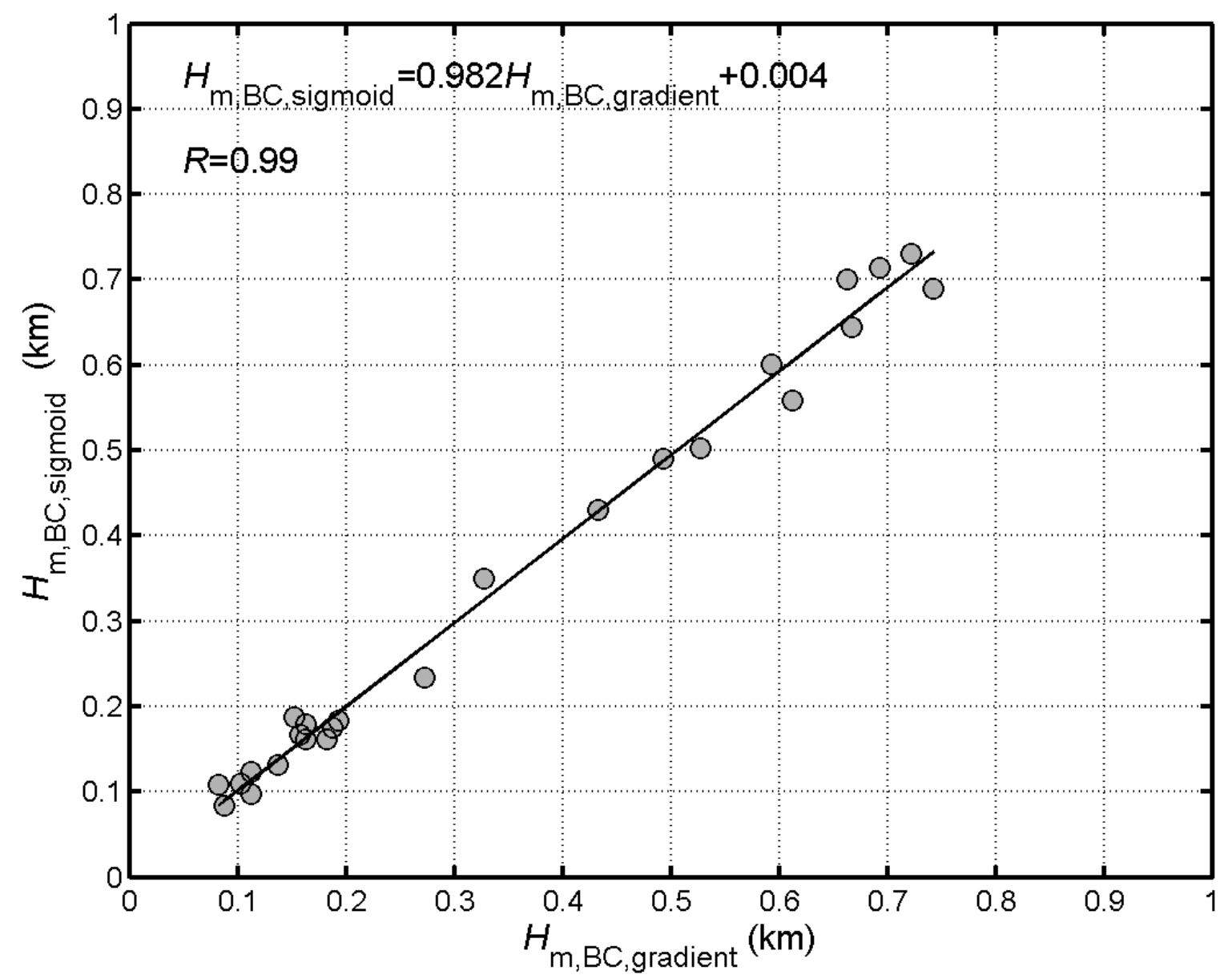

Figure S5. A comparison between mixing heights estimated from vertical profiles of $m_{\mathrm{BC}}$ using the gradient method $\left(H_{\mathrm{m}, \mathrm{BC}, \text { gradient }}\right)$ and the sigmoid function $\left(H_{\mathrm{m}, \mathrm{BC}, \text { sigmoid }}\right)$ for typical daytime profiles. 